\title{
ANÁLISE PRELIMINAR DA INCIDÊNCIA DE MENINGITE NO MUNICÍPIO DE PONTA GROSSA-PR, POR MEIO DE MODELOS MATEMÁTICOS E CENÁRIOS CLIMÁTICOS FUTUROS
}

\author{
LEITE, Maysa Lima - maysaleite@globo.com \\ Universidade Estadual de Ponta Grossa - PR \\ DAL GOBBO, Bruna Luisa - bru_gobbo@hotmail.com \\ Universidade Estadual de Ponta Grossa - PR \\ VIRGENS FILHO, Jorim Sousa - jvirgens@uepg.br \\ Universidade Estadual de Ponta Grossa - PR \\ POBB, Ketleyn - kety_pobb@hotmail.com \\ Universidade Estadual de Ponta Grossa - PR
}

\begin{abstract}
RESUMO: Os impactos causados pelo clima sobre a sociedade repercutem de diversas formas na saúde humana. Sendo assim, partindo do pressuposto de que algumas doenças infecciosas tendem a seguir um padrão sazonal de incidência, como é o caso da meningite, deve-se considerar o fato de que as mudanças climáticas que vem ocorrendo, podem impactara transmissão detais doenças. Nesta perspectiva, propôs-se no presente estudo analisar, de maneira preliminar, por meio de modelos matemáticos e simulações de cenários climáticos futuros, a influência das variáveis climáticas locais sobre a incidência de meningite no Município de Ponta Grossa, PR. Os dados climáticos foram obtidos junto ao IAPAR, e os dados epidemiológicos junto ao banco de dados SINAN. Para relacionar a influência das variáveis climáticas sobre o coeficiente de incidência da doença, foram utilizados modelos de regressão linear múltiplos e seus respectivos coeficientes de determinação. Em seguida, utilizou-se o gerador PGECLIMA_R para efetuar a simulação de cenários climáticos futuros (2012- 2101). Considerando-se os coeficientes de determinação, verificou-se valores satisfatórios para boa parte dos meses, como por exemplo, 0,85 em janeiro e 0,93 em junho, demonstrando uma maior relação entre a incidência mensal de meningite e as variáveis climáticas em alguns meses. Com a geração dos cenários climáticos futuros, pôde-se prever, de maneira preliminar, a tendência sazonal para o comportamento da doença no período de 2012 a 2101, a qual indica um aumento gradual no número de casos da doença à medida que as mudanças climáticas propostas se intensificam, especialmente no pior cenário climático.
\end{abstract}

Palavras-chave: Doenças Infecciosas; Variáveis Climáticas; Mudanças Climáticas;Gerador Climático PGECLIMA_R.

PRELIMINARY ANALYSIS OF THE INCIDENCEOF MENINGITISIN THE CITY OFPONTAGROSSA-PR, THROUGH MATHEMATICAL MODELS ANDFUTURE CLIMATE SCENARIOS

ABSTRACT: The impacts caused by climate on society bring consequences in various ways on human health. Thus, assuming that some infectious diseases tend to follow a seasonal pattern of incidence, as is the case of meningitis, one must consider the fact that climate change is already happening and may impact the transmission of such diseases. Accordingly, it was proposed in this study to examine preliminary, through the use of mathematical models and simulations of future climate scenarios, the influence of local climatic variables on the incidence of meningitis in the city of Ponta Grossa, PR. The climatic data were obtained from IAPAR, and the epidemiological data from the database SINAN. To relate the influence of climatic variables on the incidence rate of the disease, multiple linear regression models and their determination coefficients were used. Then it was used the climate generator PGECLIMA_R to perform the simulation of future climate scenarios (2012-2101). Whereas the coefficients of determination, there was satisfactory values for some months, for example, 0.85 in January and 0.93 in June, showing an increased ratio between the monthly incidence of meningitis and climate variables. With the generation of future climate scenarios, it is possible to predict, in a preliminary way, the seasonal trend for the behavior of the disease in the period of 2012-2101, which indicates a gradual increase in the number of cases of the disease as climate changes proposals intensify, especially in the worst climate scenario.

Key words: Infectious Diseases, Climate Variable, Climate Change, Climate Generator PGECLIMA_R.

\section{INTRODUÇÃO}

O clima predominante em determinada localidade compreende o conjunto de todos os elementos climáticos em uma combinação singular, que pode acentuar a incidência de certas doenças que afetam o ser humano e influenciar o crescimento, a propagação e a difusão de 
alguns organismos patogênicos (Oliveira, 2011). Segundo proposição de Rouquayrol e Almeida Filho (2003), os aspectos do clima que mais influenciam as biocenoses e, portanto, os seres vivos no processo de transmissão de doença são a temperatura média do ar, a umidade relativa do ar e a precipitação pluviométrica.

Mendonça (2000), afirma que os impactos causados pelo clima sobre a sociedade repercutem de diversas formas na saúde humana. Sendo assim, partindo do pressuposto de que algumas doenças infecciosas tendem a seguir um padrão sazonal de incidência, como é o caso da meningite (Paula, 2003), deve-se considerar o fato de que as mudanças climáticas que vêm ocorrendo,podem impactara transmissão detais doençase sua distribuiçãogeográfica devido, por exemplo,àsmudanças na temperaturamédia do ar e na incidência dechuva (Morand e col., 2013).Tais alterações climáticas têm, então, o potencial de aumentar o desafio de prevenir e controlar surtos de doenças infecciosas (Ebie col., 2013).

Segundo dados exibidos pelo Painel Intergovernamental de Mudanças Climáticas - IPCC, no seu quarto Relatório de Avaliação das Mudanças Climáticas do planeta, denominado IPCC-AR4 (IPCC, 2007), os resultados alertam para um aumento médio global das temperaturas do planeta, entre $1,8^{\circ} \mathrm{C}$ e $4,0^{\circ} \mathrm{C}$ até 2100 , baseados respectivamente em uma perspectiva mais otimista e pessimista para o futuro do clima do planeta. O mesmo indica ainda um aumento na intensidade de chuvas para o sul do Brasil e uma diminuição para o Nordeste brasileiro.

Como consequência, de tais mudanças climáticas, além de epidemias de doenças emergentes, podem surgir também epidemias de doenças reemergentes ocorridas em várias partes do planeta (Luna, 2002). Sendo assim, é de extrema importância que seja incentivada uma interação mais sinérgica entre climatologistas e ecologistas de doenças infecciosas já que os problemas envolvidos são cientificamente um desafio, porém, não insolúveis. O produto desta interação sinérgica tem o potencial para atenuar e reduzir em níveis significativosum futuro sofrimento humano (Rodó e col., 2013).

A partir de todas as descobertas já obtidas em estudos realizados, e às confirmações já encontradas entre a relação de influência das variáveis climáticas sobre a saúde humana, os questionamentos existentes a respeito das mudanças climáticas globais e de suas repercussões nas condições de vida da humanidade ganham destaque no cenário atual e despertam a atenção de inúmeros estudiosos mundialmente, considerando a extrema relevância e complexidade do assunto.

Neste sentido, devido à expressiva importância de tais estudos sobre a interação entre clima e saúde, principalmente diante da intensificação do aquecimento planetário, cada vez mais são projetados cenários climáticos futuros (Mendonça, 2005), os quais são baseados em modelos matemáticos, que consistem na representação matemática do que acontece na natureza a partir de um modelo conceitual, idealizado com base no levantamento de dados do sistema real, tendo como objetivo uma melhor compreensão da realidade (Iritani, 1999).

Para a elaboração e perturbação destes cenários climáticos futuros são utilizados geradores climáticos, que são definidos por Baena e col. (2005),como modelos de simulação matemática, com os quais obtém-se a geração de séries sintéticas de dados climáticos, com as mesmas características estatísticas da série histórica. Dentre os geradores já criados, destaca-se o PGECLIMA_R - Gerador Estocástico de Cenários Climáticos (Virgens Filho e col., 2013), que além de simular dados climáticos, gera também cenários climáticos futuros a partir de perturbações estatísticas nas variáveis climáticas.

A simulação de tais cenários torna-se relevante, principalmente, para países tropicais como o Brasil, que têm maior tendência a sofrer com o aumento de doenças infecciosas como a meningite, que demonstra relação íntima com as condições climáticas,(Mendonça, 2005).

A meningite consiste na inflamação das membranas que envolvem o cérebro e a medula espinhal e pode ser causada por agentes infecciosos, como bactérias, vírus e fungos, entre outros, e agentes não-infecciosos, como por exemplo, traumatismo. As meningites causadas por bactérias e vírus, são as mais importantes do ponto de vista da saúde pública, pela magnitude de sua ocorrência e potencial de produzir surtos. Podem ser transmitidas de pessoa 
para pessoa (vias respiratórias), por gotículas e secreções da nasofaringe, havendo necessidade de contato íntimo ou contato direto com as secreções respiratórias do paciente (Brasil, 2005).

As várias etiologias de meningites são encontradas no mundo todo, porém, sua incidência depende de fatores como o agente infeccioso, ocorrência de aglomerados populacionais, características socioeconômicas da população e das condições do meio ambiente, em especial, do clima (Brasil, 2005). Tal patologia persiste como importante problema de saúde pública, já que está relacionada com uma série de complicações imediatas e tardias, que podem culminar em danos irreversíveis ao sistema nervoso central, ou levar o indivíduo à morte (Vieira, 2001).

Dentre as várias etiologias existentes de meningite, a bacteriana é a principal responsável por complicações tardias, destacando-se sequelas neurológicas (Kesser e col., 1999). Já a meningite viral caracteriza-se por um quadro clínico de alteração neurológica, que, em geral, evolui de forma benigna (Secretaria de estado da saúde de São Paulo, 2006). Outro fato a ser considerado é a incidência predominante de meningites bacterianas no inverno e de meningites virais no verão (Santos, 2007).

Sendo assim, considera-se de grande importância o estudo do comportamento da doença, tomando como base estudos como o de Labiak e col. (2007), realizado em Ponta Grossa, de 2001 a 2005, onde foram encontrados valores de letalidade significativos para os casos de meningite no ano de 2002, (17,24\%) e nos anos de 2004 e 2005,(13,33\%), e considerando ainda a estreita relação entre a incidência da meningite e as variáveis climáticas.

Apesar de considerar as alterações climáticas comoum fenômeno global,seus efeitosvariam conforme cada localidade (Morand e col., 2013) e ferramentas cada vez mais precisas e atuais como os geradores de cenários climáticos permitem antecipar problemas de saúde pública, tornando-se de grande importância a análise da incidência da doença juntamente com o clima da região.

Desse modo, propôs-se no presente estudo analisar, por meio de modelos matemáticos e simulações de cenários climáticos futuros, a influência das variáveis climáticas locais sobre a incidência de meningite no Município de Ponta Grossa, PR.

\section{MATERIAL E MÉTODOS}

Para o desenvolvimento do presente estudo foram analisados dados climatológicos históricos das variáveis climáticas precipitação pluviométrica $(\mathrm{mm})$, umidade relativa do ar $(\%)$ e temperatura média do ar $\left({ }^{\circ} \mathrm{C}\right)$, referentes ao período de 1980-2011, da cidade de Ponta Grossa - PR, a qual possui um clima caracterizado como Cfb na classificação de Köppen, o qual, segundo dados do IAPAR (2000), citado por Cruz (2007) corresponde ao clima temperado propriamente dito com temperatura média do ar no mês mais frio abaixo de $18^{\circ} \mathrm{C} \mathrm{e}$ temperatura média do ar no mês mais quente abaixo de $22^{\circ} \mathrm{C}$, sem estação seca definida.

Tais dados foram obtidos junto à Estação Agrometeorológica de Ponta Grossa situada no Parque Estadual de Vila Velha, com coordenadas geográficas de $25^{\circ} 13^{\prime}$ de latitude sul e $50^{\circ} 01^{\prime}$ de longitude oeste e 880 metros de altitude e sob a responsabilidade do Instituto Agronômico do Paraná - IAPAR.

Os dados climáticos obtidos serviram de base para a elaboração dos modelos matemáticos para a estimativa dos coeficientes de incidência da meningite. Vale ressaltar que como os dados epidemiológicos disponíveis se referiam apenas ao período de 2006 a 2011, os modelos mensais utilizaram dados climáticos correspondentes somente a este período. No entanto, para a simulação dos cenários climáticos futuros de 2012 a 2101, foi utilizada a série histórica de dados climáticos referente ao período de 1980-2011.

Os registros epidemiológicos a respeito da meningite, referentes ao período de 2006-2011, foram obtidos a partir das notificações e investigações de agravos de meningite do banco de dados SINAN (Sistema de Informações de Agravos de Notificação) junto ao Setor da Vigilância 
Epidemiológica e Controle de Doenças, pertencente à $3^{a}$ Regional de Saúde da cidade de Ponta Grossa - PR. Deste banco de dados, foram selecionadas as seguintes variáveis: classificação do caso/ etiologia (tipo de meningite), sendo a amostra composta de 356 casos notificados da doença, incluindo todas as etiologias da doença descritas no item número 51 da ficha de notificação de meningite (Figura 1). Para a utilização de tais informações, a proposta da Pesquisa foi encaminhada ao Comitê de Ética em Pesquisa com Seres Humanos (COEP) da Universidade Estadual de Ponta Grossa (UEPG), e devidamente aprovada, sob o número do protocolo 04619/12. Os dados obtidos foram utilizados para fins exclusivos de pesquisa científica preservando-se a identidade dos sujeitos, de acordo com a Resolução no 196/96 do Conselho Nacional de Saúde.

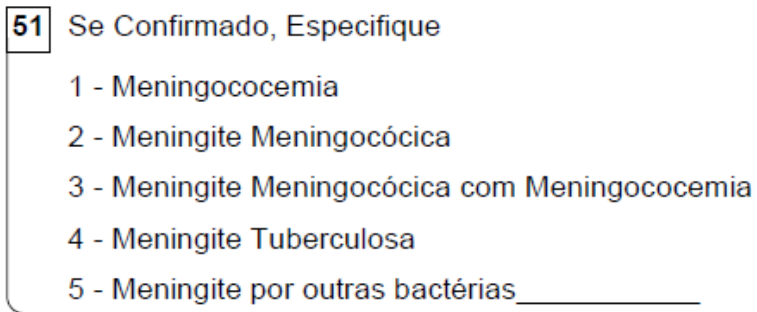

Figura 1 -Etiologias de meningite encontradas no item número 51 da Ficha de Investigação de Meningite do Sistema de Informações de Agravos de Notificação da $3^{a}$ Regional de Saúde da cidade de Ponta Grossa - PR.

Fonte: Ficha de Investigação de Meningite do Sistema de Informações de Agravos de Notificação.

Inicialmente, os dados das variáveis climáticas, juntamente com os dados das notificações de casos de meningite foram submetidos a triagem e avaliação, para posteriormente receber tratamento estatístico. Para a interpretação da taxa mensal de indivíduos afetados pela patologia (meningite) empregou-se o Coeficiente de Incidência Mensal $\left(\mathrm{CI}_{t}\right)$, sendo que os cálculos de tal coeficiente, para o período em estudo (2006-2011), foram expressos por 10.000 habitantes. Os coeficientes foram calculados pela seguinte equação (Rouquayrol; Almeida Filho, 2003):

$$
C I_{t}=\left(\text { Númerodecasosnovos } \times 10^{n} / \text { populaçãoexpostaaorisco }\right) \mathrm{Eq} \text {. }
$$

Em que $n$, determina o tamanho da amostra da população e $t$, um mês do ano. Para a realização do cálculo, considerou-se como população exposta ao risco, projeções baseadas nos censos realizados pelo Instituto Brasileiro de Geografia e Estatística - IBGE, no referido período.

As notificações dos casos de meningite foram avaliadas juntamente com os dados históricos referentes às variáveis climáticas:precipitação pluviométrica $(\mathrm{mm})$, umidade relativa do ar $(\%)$ e temperatura média do ar $\left({ }^{\circ} \mathrm{C}\right)$, para a análise de possíveis interferências climáticas na incidência de meningite. Para tanto, realizou-se o estudo de modelos matemáticos mensais de regressão linear múltiplapara testar a influência destas variáveis sobre a incidência da doença. O modelo teórico em questão pode ser representado por (Downing; Clark, 2003):

$$
Y_{i}=\beta_{0}+\beta_{i 1} X_{i 1}+\beta_{i 2} X_{i 2}+\beta_{i 3} X_{i 3}+\epsilon_{i}
$$

Em que: $Y$ é a variável explicada ou dependente (no caso, coeficiente de incidência), ou seja,é o valor que se quer atingir; $\beta_{0}, \beta_{1}, \beta_{2}$ e $\beta_{3}$ são os parâmetros desconhecidos; $X_{i 1}, X_{i 2}$ e $X_{i 3}$ são as variáveis explicativas ou independentes (no caso, variáveis climáticas), que representam o fator explicativo na equação e $\epsilon$ é a variável aleatória residual, na qual procura-se incluir todas as influências no comportamento da variável $Y$ que não podem ser explicadas linearmente pelo comportamento das variáveis $\mathrm{X}_{\mathrm{i} 1}, \mathrm{X}_{\mathrm{i} 2}$ e $\mathrm{X}_{\mathrm{i} 3}$ e os possíveis erros de medição.

Concomitantemente à elaboração dos modelos matemáticos mensais, realizou-se o cálculo dos coeficientes de determinação para cada modelo, para testá-los quanto à suas capacidades de justificar os coeficientes de incidência de meningite a partir das variáveis climáticas. 
Em seguida, utilizou-se o Gerador Estocástico de Cenários Climáticos - PGECLIMA_R (Virgens Filho e col., 2013) para efetuar a simulação de dois cenários climáticos futuros, divididos em 3 períodos com intervalos de 30 anos cada a partir de 2012 até 2101 (períodos de 2012-2041; 2042-2071; 2072-2101), baseados no melhor e no pior cenários divulgados pelo $4^{\circ}$ relatório do IPCC, além da geração de um terceiro cenário normal, caso não ocorram as alterações propostas pelo IPCC.

Os dados climáticos simulados para o município de Ponta Grossa, PR considerando-se o pior e o melhor cenários, contemplaram um aumento de temperatura média do ar, conforme projetado pelo 40 relatório do IPCC. Também foram considerados um aumento de precipitação pluviométrica ao longo dos anos, e um decréscimo da umidade relativa do ar, considerando-se que para cada elevação de $1^{\circ} \mathrm{C}$, ocorre um aumento aproximado de $10 \%$ da precipitação e um decréscimo aproximado de 6,25\% de umidade relativa do ar (Pyke, 2005).

Deforma mais detalhada, os $4,0{ }^{\circ} \mathrm{C}$ de aumento de temperatura média do ar, o aumento de $40 \%$ da precipitação pluviométrica, assim como um decréscimo de aproximadamente $25 \%$ de umidade relativa do ar, para o pior cenário, foram diluídos ao logo das simulações dos 3 períodos (90 anos) a serem avaliados. 0 mesmo se verificou para o melhor cenário, onde o aumento de temperatura média do ar de $1,8{ }^{\circ} \mathrm{C}$, o aumento de $18 \%$ da precipitação pluviométrica, assim como um decréscimo de aproximadamente $11,25 \%$ de umidade relativa do ar, também foram diluídos ao logo das simulações.

Visando estabelecer uma relação entre a incidência de meningite e o clima e considerando-se as mudanças climáticas que podem ocorrer no futuro, os dados climáticos obtidos por meio do Gerador PGECLIMA_R, conforme as perturbações climáticas mencionadas acima foram aplicados aos modelos matemáticos previamente determinados, permitindo que os coeficientes sazonais médios de incidência de meningite fossem calculados para o período 2012 a 2101 .

Por fim, efetuou-se a conversão dos coeficientes médios de incidência para número médio de casos de meningite para facilitar a compreensão do leitor quanto aos cenários futuros da doença esperados para o município de Ponta Grossa, PR.

\section{RESULTADOS E DISCUSSÃO}

No que se refere ao número de notificações de casos confirmados de meningite durante o período avaliado no presente estudo, foram registrados, a partir do banco de dados no SINAN, 356 casos de meningite, considerando-se todas as etiologias da doença. Destes casos, 100 foram registrados em 2006, 79 em 2007, 48 em 2008, 40 em 2009, 55 em 2010 e 34 casos em 2011.

São apresentados, na Figura $2 \mathrm{~A}$, os coeficientes mensais de incidência média de meningite do período de 2006 a 2011 em Ponta Grossa. Observou-se que o mês de novembro apresentou a maior incidência da doença $(0,23 / 10.000$ habitantes), seguido pelos meses de junho, março e outubro, que apresentaram valores de 0,21, 0,18 e 0,18/10.000 habitantes, respectivamente.

Analisando inicialmente o período mais quente, observa-se que os meses de março, outubro e novembro apresentaram valores de precipitação pluviométrica consideráveis $(111,27$, 140,83 e $119,73 \mathrm{~mm}$ respectivamente). Novembro apresentou umidade relativa do ar mais baixa que a maioria dos meses $(75,26 \%)$, enquanto março e outubro apresentaram valores ligeiramente menor que os meses de inverno (79,92\% e $78,72 \%$, respectivamente) (Figuras $2 \mathrm{~B}, 2 \mathrm{C}$ ). Valores os quais, condizem com um panorama geral da variável para a região, que encontra-se normalmente na faixa de 75 a $80 \%$, segundo dados de Cruz (2007). Os três meses obtiveram temperatura média do ar elevada, em comparação com os meses invernais, $\left(21,20^{\circ} \mathrm{C}, 18,84^{\circ} \mathrm{C}\right.$ e $20,18^{\circ} \mathrm{C}$ respectivamente) (Figura 2D). Tais valores concordam com a média esperada para a região, já que, segundo o mesmo autor referido anteriormente, a média encontrada para o mês mais quente da região, está abaixo de $22^{\circ} \mathrm{C}$.

Considerando tal comportamento das variáveis, a alta incidência média de meningite encontrada nos meses de março, outubro e novembro poderia ser atribuída ao aumento do 
número de casos de meningite viral nesse período. Assim como no estudo de Stocco e col. (2010), realizado também na localidade de Ponta Grossa, onde o elevado coeficiente de incidência da meningite, em meses com características semelhantes às das variáveis climáticas de março, outubro e novembro foi atribuído à ocorrência de meningite viral. É importante destacar que a meningite viral pode caracterizar-se, segundo Brasil (2002), pela elevada ocorrência de casos no final do verão e começo do outono.

Conforme proposição de Mendonça e Paula (2008) há estreita relação entre a ocorrência de meningites virais e a temperatura do ar, já que a frequência de casos de meningite viral se eleva nos meses mais quentes do ano, devido, normalmente, à prevalência do Enterovírus, mais comum causador da meningite, o qual apresenta comportamento sazonal, predominando em temperaturas mais altas, condição favorável à sua proliferação. Podendo, entretanto, ocorrer também, em número menor, nas outras estações do ano (Secretaria de estado da saúde de São Paulo, 2006).

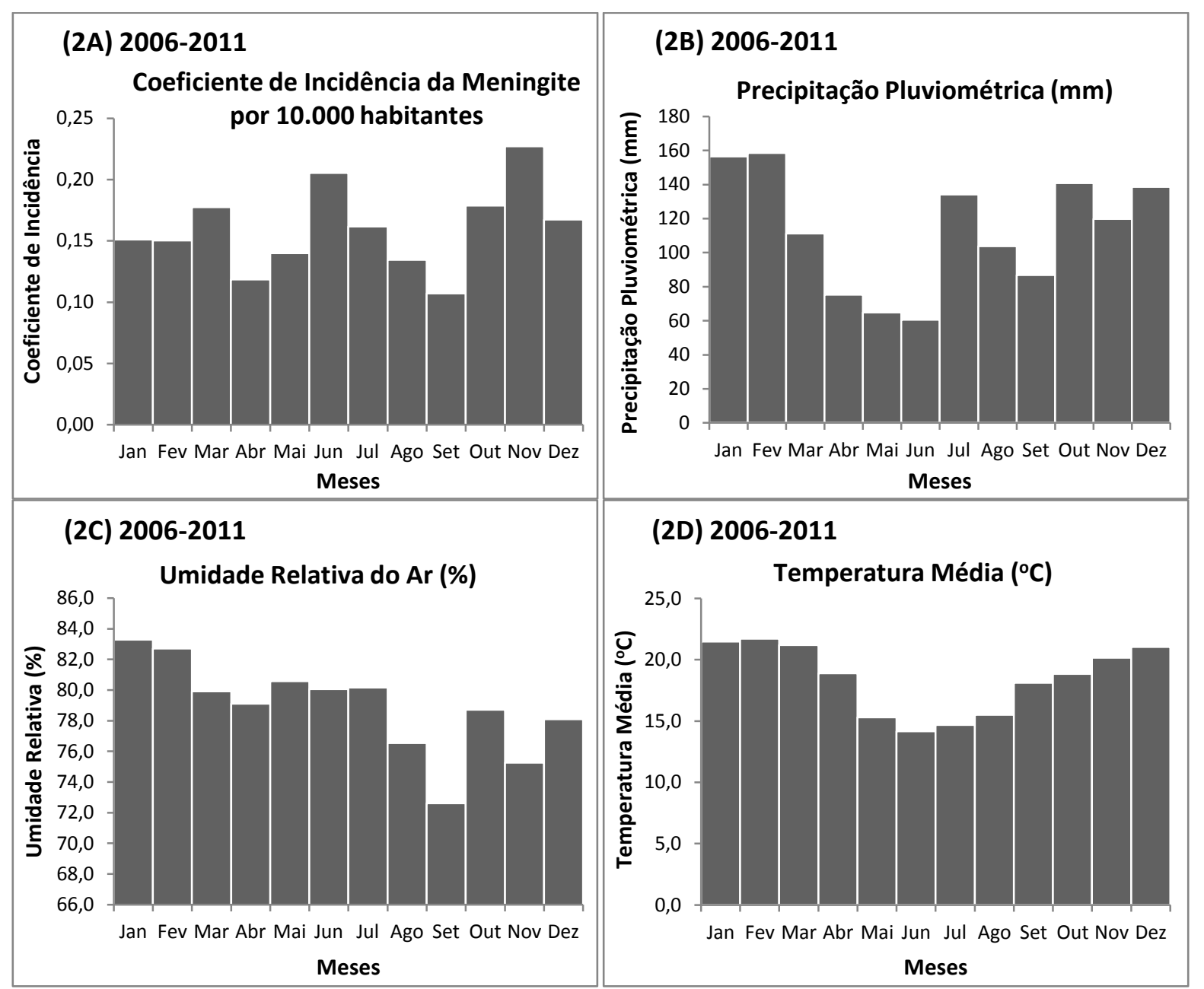

Figura 2 -Variação média mensal dos coeficientes de incidência de meningite (A), precipitação pluviométrica (B), umidade relativa do ar (C) e temperatura média do ar (D), Ponta Grossa-PR, 20062011.

A transmissão do Enterovírus, segundo Dalzochio (2013) se dá também pela via fecal-oral, podendo ser eliminados em grandes quantidades nas fezes de indivíduos infectados, favorecendo a contaminação de recursos hídricos. Portanto, sua incidência pode tornar-se maior no verão, já que nesse período, a tendência de entrar em contato com água e bebê-la é maior, e esta pode estar contaminada.

Durante o mês de Junho registrou-se o valor de precipitação pluviométrica mais baixo, quando comparado com os outros meses $(60,63 \mathrm{~mm})$, constatou-se valor elevado de umidade relativa 
do ar $(80,06 \%)$ e temperatura média do ar mais baixa em relação aos outros meses $\left(14,17^{\circ} \mathrm{C}\right)$, (Figuras 2B, 2C e 2D). Sendo assim, a alta incidência de meningite no referido mês, poderia ser atribuída a essa combinação, resultando no aumento do número de casos de meningite bacteriana, cujo agente etiológico é favorecido por tais condições climáticas.

No estudo de Mendonça e Paula (2008) também verificou-se a prevalência de casos de meningite bacteriana, ou meningite meningocócica, nos meses invernais, provavelmente pelo confinamento maior da população e pelo número aumentado de infecções respiratórias que facilitam a transmissão da doença. Do mesmo modo, Paula (2003) afirma que a meningite bacteriana, causada pelo meningococo ocorre durante todo o ano, sendo, porém, mais frequente nos meses frios, devido ao seu modo de transmissão, o qual se deve por contato direto de pessoa para pessoa por via respiratória, através de gotículas e secreções da nasofaringe, fato de maior ocorrência no inverno.

Durante o período avaliado, setembro apresentou a menor incidência média de meningite, sendo o coeficiente de 0,11/10.000 habitantes, seguido de abril, que tem como incidência média mensal o coeficiente de 0,12/10.000 habitantes(Figura 2A). Concomitantemente, setembro apresentou também a menor umidade relativa do ar de todos os meses $(72,61 \%)$,elemento de possível relação com a baixa incidência encontrada (Figura $2 \mathrm{C}$ ). Estes dados concordam parcialmente com o estudo de Dantas e col. (2007), o qual alega que é possível que o aumento da temperatura média do ar e a redução da umidade relativa do ar, possam contribuir para reduzir o número de ocorrências desta enfermidade, durante a primavera. Tanto abril quanto setembro apresentaram valores relativamente baixos de precipitação pluviométrica $(86,93$ e $75,30 \mathrm{~mm}$, respectivamente), além de também apresentar, valores semelhantes e moderados de temperatura média do ar $\left(18,84\right.$ e $18,89{ }^{\circ} \mathrm{C}$, respectivamente) (Figura $2 \mathrm{~B}$ e $2 \mathrm{D}$ ).

Todavia, é fato relevante para traçar o comportamento de uma doença, considerar que inúmeras variáveis aleatórias são responsáveis pela incidência dessa doença. Assim como reconhece Grasso e col. (2012), as mudanças climáticas são apenas um dos muitos fatores importantes que influenciam a incidência de doenças infecciosas, além de fatores sóciodemográficos (migrações humanas, aglomerados populacionais, transporte, alimentação), ou de influências ambientais (desmatamento, condições de água, urbanização).Porém, vale ressaltar, que no caso do estudo em questão, as variáveis como, condições socioeconômicas e comportamentais da população não foram avaliadas.

Na Tabela 1 são apresentados os modelos matemáticos para estimativa dos coeficientes mensais de incidência de meningite em Ponta Grossa-PR, no período de2006 a 2011 em função das variáveis climáticas: precipitação pluviométrica $(\mathrm{mm})$, umidade relativa do ar (\%) e temperatura média do ar $\left({ }^{\circ} \mathrm{C}\right)$.

Considerando-se os modelos para os coeficientes mensais de incidência de meningite na localidade em estudo, observa-se que em boa parte dos meses foram obtidos ajustes satisfatórios dos modelos, fato observado pela obtenção de valores para o coeficiente de determinação $\left(R^{2}\right)$, como, 0,85 em janeiro, 0,93 em junho, e 0,96 em agosto, indicando assim, que os modelos matemáticos obtidos, baseados nos elementos climáticos (precipitação pluviométrica $(\mathrm{mm})$, umidade relativa do ar $(\%)$ e temperatura média do ar $\left({ }^{\circ} \mathrm{C}\right)$ ) foram capazes de explicar satisfatoriamente os coeficientes mensais de incidência de meningite nestes meses. 


\begin{tabular}{|c|c|c|}
\hline & Modelo de Regressão Linear Múltiplo & $\mathrm{R}^{2}$ \\
\hline Janeiro & $\mathrm{CI}=-6,429160+0,155724 * T M E D+0,036790 * \mathrm{UR}+0,001099 * \mathrm{PREC}$ & 0,8594 \\
\hline Fevereiro & $\mathrm{CI}=4,4763809-0,0672492 *$ TMED-0,0354034*UR+0,0004190*PREC & 0,4421 \\
\hline Março & $\mathrm{CI}=-5,007+0,1133 * \mathrm{TMED}+0,03490 * \mathrm{UR}-0,00004796 * \mathrm{PREC}$ & 0,4903 \\
\hline Abril & $\mathrm{CI}=-1,0023340+0,0892002 *$ TMED $-0,0079180 * \mathrm{UR}+0,0008446 *$ PREC & 0,7191 \\
\hline Maio & $\mathrm{CI}=0,8289458-0,0404982 * \mathrm{TMED}-0,0024363 * \mathrm{UR}+0,0019774 * \mathrm{PREC}$ & 0,8699 \\
\hline Junho & $\mathrm{CI}=-0,6357508+0,1049267 *$ TMED $-0,0085939 * \mathrm{UR}+0,0007283 * \mathrm{PREC}$ & 0,9305 \\
\hline Julho & $\mathrm{CI}=0,1041211+0,0359747 *$ TMED $-0,0061430 * \mathrm{UR}+0,0001625 *$ PREC & 0,1900 \\
\hline Agosto & $C I=-1,1295409+0,0908014 *$ TMED $-0,0026093 * U R+0,0005620 *$ PREC & 0,9686 \\
\hline Setembro & $\mathrm{CI}=-0,2859123+0,0056724 *$ TMED $+0,0042807 * \mathrm{UR}-0,0001736 * \mathrm{PREC}$ & 0,2413 \\
\hline Outubro & $\mathrm{CI}=-1,812269-0,017002 *$ TMED $+0,034020 *$ UR-0,002583*PREC & 0,5440 \\
\hline Novembro & $C I=0,475067-0,115371 *$ TMED $+0,023664 * U R+0,002519 *$ PREC & 0,6760 \\
\hline Dezembro & $\mathrm{CI}=-2,642478+0,064274 * \mathrm{TMED}+0,020716 * \mathrm{UR}-0,001141 * \mathrm{PREC}$ & 0,6480 \\
\hline
\end{tabular}

Tabela 1 - Modelos de Regressão Linear Múltiplo e seus respectivos coeficientes de determinação $\left(R^{2}\right)$ para a estimativa dos Coeficientes Mensais de Incidência de Meningite no período de 2006-2011, na localidade de Ponta Grossa-PR

Legenda: CI: Coeficiente de Incidência Média Mensal; TMED: Temperatura Média do Ar; UR: Umidade Relativa do Ar; PREC: Precipitação Pluviométrica.

Valores menos satisfatórios observados, por exemplo, em julho e setembro $(0,19$ e 0,24$)$, indicam que nesses meses as variáveis climáticas não foram suficientes para predizer a ocorrência da doença, quando considera-se que outras variáveis importantes também estão relacionadas à sua manifestação, como condições socioeconômicas, comportamentais, ambientais, e qualidade de vida da população.

Os resultados alcançados mostram-se coerentes com os resultados apresentados por Stocco e col. (2010), onde, do mesmo modo, obteve-se valores satisfatórios para os coeficientes de determinação, em boa parte dos meses, quando considerados os modelos propostos, também abordando a relação entre as variáveis climáticas precipitação pluviométrica $(\mathrm{mm})$, umidade relativa do ar (\%) e temperatura média do ar $\left({ }^{\circ} \mathrm{C}\right)$ e os casos de meningite em Ponta Grossa. Ainda segundo os autores referidos anteriormente, valores superiores a 0,74 foram alcançados na maioria dos meses, tendo-se observado, porém, valores menos satisfatórios em alguns meses como, por exemplo, 0,20 em dezembro.

Segundo os dados apresentados na Figura 3 pode-se observar um possível comportamento esperado para a patologia nos anos que se seguem (2012-2101), subdivididos em períodos de 30 anos, em termos de número de casos de meningite, para as quatro estações do ano (verão (dez/jan/fev), outono (mar/abr/mai), inverno(jun/jul/ago) e primavera (set/out/nov)), conforme a variação dos elementos climáticos simulados (precipitação pluviométrica $(\mathrm{mm})$, umidade relativa do ar (\%) e temperatura média do ar $\left({ }^{\circ} \mathrm{C}\right)$ ), caso se confirmem as previsões para o melhor e o pior cenários do IPCC propostos em seu 40 relatório, e também o possível comportamento da patologia caso as variáveis climáticas não sofram as alterações preditas pelos cenários do IPCC. 


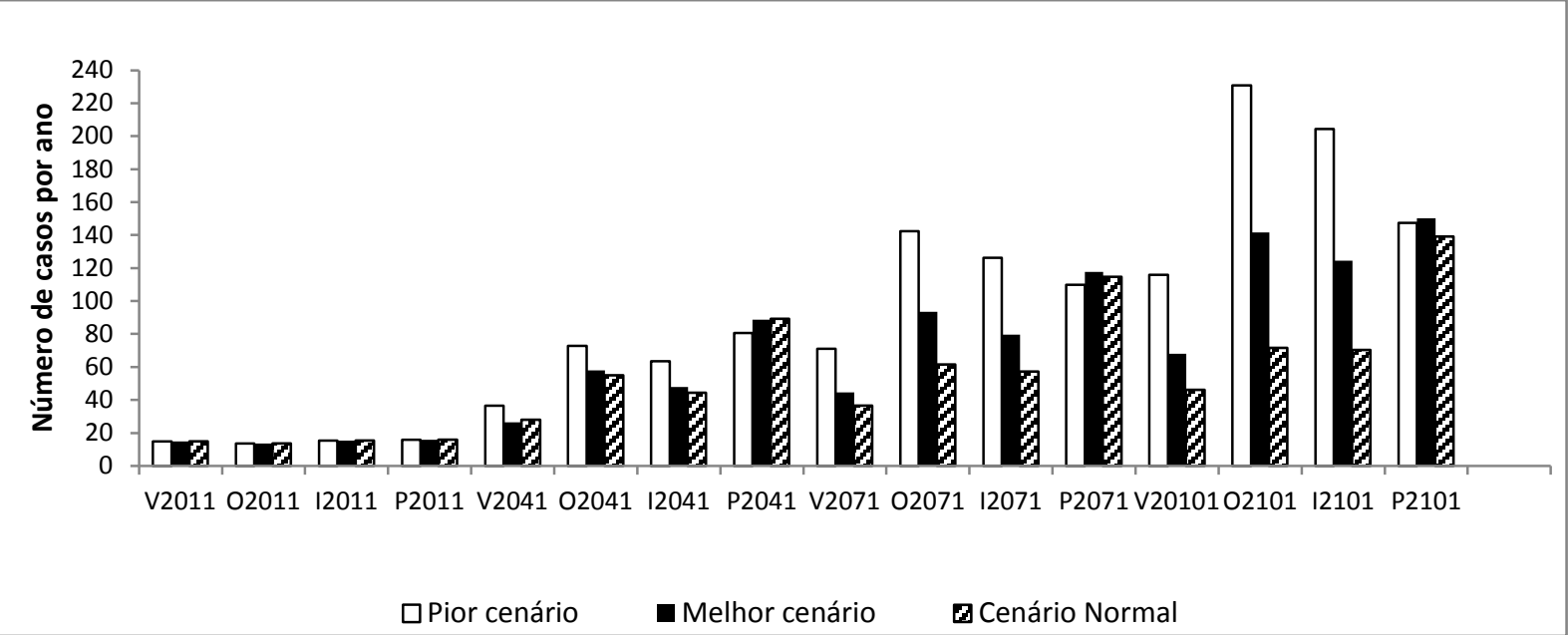

Legenda: V: Verão; O: Outono; I: Inverno; P: Primavera.

Figura 3 - Sazonalidade dos casos de Meningite, simulados para Ponta Grossa no período de 2012 a 2101, segundo cenário normal e segundo o melhor e o pior cenários sugeridos pelo 40 relatório do IPCC.

Observa-se, como esperado, um aumento gradual na ocorrência da doença com o passar dos anos, concordando com a proposição de Mendonça (2005), que indica uma possível intensificação na incidência de uma série de doenças bastante comuns no cenário brasileiro, um país tropical, num contexto de aquecimento global como o anunciado para o século que se inicia, como a febre-amarela, a cólera, e inclusive a meningite.

É importante ressaltar que além da possível alteração das variáveis climáticas, o crescimento populacional projetado para o município de Ponta Grossa, aponta para totais de 465.445, 604.795 e 744.145 habitantes para os três períodos em estudo, conforme projeções do IBGE, o que pode influenciar também no aumento do número de casos da patologia em questão.

Uma análise mais detalhada do comportamento da patologia em questão, ao longo dos anos simulados, pode ser obtida observando-se as tendências para os três cenários climáticos futuros, em cada estação do ano separadamente, conforme representado na Figura 4, facilitando assim a compreensão e entendimento da possível dinâmica da doença no futuro.
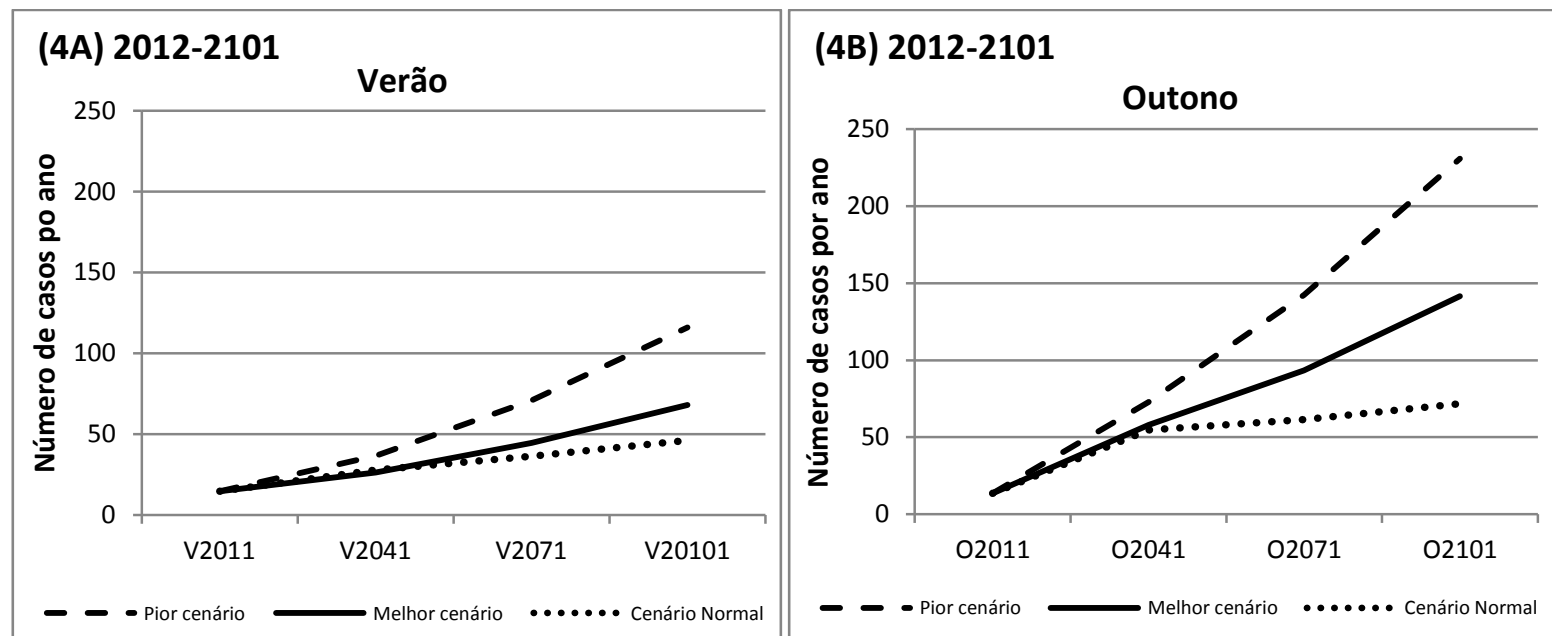

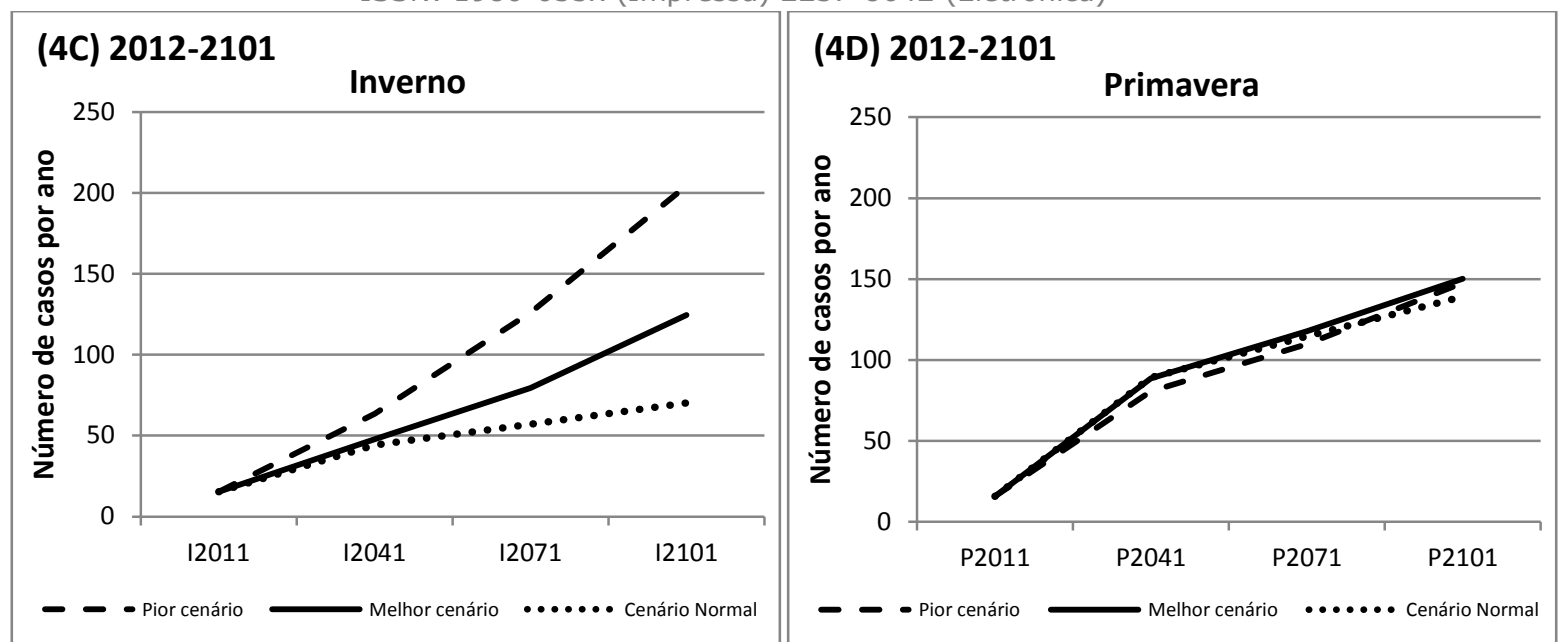

Legenda: V: Verão; O: Outono; I: Inverno; P: Primavera.

Figura 4 - Variação sazonal dos casos de Meningite (verão (A), outono (B), inverno (C) e primavera (D)), simulados para Ponta Grossa no período de 2012 a 2101, segundo cenário normal e segundo o melhor e o pior cenários sugeridos pelo 40 relatório do IPCC.

Observa-se que no outono (mar/abr/mai), no inverno (jun/jul/ago) e no verão (dez/jan/fev) o maior aumento no número de casos da doença, com o passar do tempo, encontra-se expresso no pior cenário predito pelo IPCC, seguido pelo melhor cenário, e por fim, o menor aumento do número de casos, está no cenário normal.

Durante a primavera (set/out/nov), observa-se, porém, um comportamento diferenciado, quando compara-se a evolução do número de casos nos três cenários, constatando-se nesta estação o menor nível de alterações entre estes, ou seja, os três revelaram totais muito próximos. Verifica-se que há uma diminuição do número de casos referentes ao pior cenário, ao mesmo tempo que há um aumento do número de casos considerando-se o cenário normal,quando comparados com as outras estações.

Esta constatação é preocupante, uma vez que, mesmo que não ocorresse nenhuma alteração climática sugerida pelo IPCC, o total de casos da doença na primavera seria mais elevado do que nas outras estações. No entanto, deve-se levar em consideração que os modelos matemáticos ajustados para os meses da primavera (set/out/nov) apresentaram valores para os coeficientes de determinação variando entre baixos e medianos, ou seja, 0,2413, 0,5440 e 0,6760 , respectivamente, podendo ter levado à geração dos 3 cenários com um ajuste menos satisfatório e consequentemente, um total de casos bastante próximo quando comparados ente si, nesta estação do ano.

Analisando o outono (mar/abr/mai),observa-se um aumento gradativo no número de casos esperados para os três períodos do pior cenário, chegando ao número de 231 casos da patologia durante o último período (2072-2101). Correspondendo este, ao maior valor de número de casos da doença encontrado, diante de todos os cenários simulados. Encontram-se também valores consideráveis, em comparação com as outras estações,para os outros dois cenários simulados, alcançando os valores de 142 casos para o melhor cenário e 72 casos para o cenário normal, no último período simulado (2072-2101). Nota-se então, para o pior cenário simulado, uma evolução preocupante na quantidade de casos de meningite esperados para esta estação do ano(Figura 4B).

No inverno (jun/jul/ago), o número de casos de meningite também se apresenta com uma tendência de elevação considerável, distribuída ao longo dos três períodos correspondentes ao pior cenário, chegando a valores como 204 casos esperados da doença no último período simulado (2072-2101). Para o melhor cenário, e o cenário normal são esperados também um aumento gradual no número de casos ao longo dos períodos simulados, chegando, finalmente, a valores correspondentes a 124 e 70 casos respectivamente. Nota-se então, que para esta estação o número de casos esperados para a patologia, de uma maneira geral,também é elevado(Figura 4C). 
Para a primavera (set/out/nov) e para o verão (dez/jan/fev), os valores seguem, igualmente, uma tendência de aumento gradual durante os períodos consecutivos de trinta anos. Os números de casos encontrados para o último período simulado (2072 e 2101) mostram-se significativos, chegando a 148 e 116 casos, respectivamente, para o pior cenário. Tendo em vista o melhor cenário encontram-se valores como 150 casos na primavera e 68 casos no verão. Já para o cenário normal observam-se valores de 139 e 46 casos respectivamente. Vale ressaltar que na primavera, o melhor cenário e o cenário normal apresentam uma tendência maior de elevação, para seus três períodos, no número que casos da doença, que as outras estações. Fato que faz com que o número de casos dos três cenários simulados para essa estação permaneçam mais equiparados que nas outras estações (Figuras 4A e 4D), conforme já discutido anteriormente.

Vale ressaltar que as características climáticas que influenciam a evolução positiva do número de casos da meningite para as estações do ano à medida que as mudanças climáticas sugeridas intensificam-se, condiz com as condições típicas dos meses mais quentes do ano, os quais, segundo Mendonça e Paula (2008) e vários outros autores, são favoráveis à incidência de meningite viral. Sendo assim, a meningite viral, poderia então, estender sua ocorrência, devido às novas condições climáticas, para mais estações durante o ano, as quais antes das alterações climáticas possuíam condições menos favoráveis ao aparecimento da doença, aumentando desse modo, seu número de casos.

Ainda segundo proposição de Mendonça e Paula (2008), as mudanças climáticas ocorridas em todo o Paraná, e o aumento na temperatura média do ar nos últimos anos, pode ser favorável à elevação do número de casos de meningites virais causadas por enterovírus, cuja incidência é maior no verão. Diferentemente, as meningites que prevalecem no inverno, dentre as quais se destaca a meningocócica, poderiam ter sua incidência reduzida, já que além da incidência das infecções respiratórias que facilitam a transmissão do meningococo se reduzir, o confinamento de pessoas em ambientes fechados também seria menor, diminuindo assim o risco de transmissão.

De acordo com um panorama geral dos valores obtidos para as quatro estações do ano, nos três cenários climáticos simulados, o comportamento da patologia torna-se preocupante para o bem estar da população. Busca-se compreender então, a possível interferência do clima sobre o comportamento da doença, porém, sem desconsiderar a influência de outras variáveis sobre a mesma, o que torna a previsão de comportamento da patologia suscetível tanto a mudanças climáticas, como das outras inúmeras, e não menos importantes variáveis.

\section{CONCLUSÃo}

Após a análise da associação entre a incidência de meningite e os dados referentes às variáveis climáticas, conclui-se que:

- Mediante os resultados obtidos a partir dos modelos matemáticos, e de seus respectivos coeficientes de determinação, observou-se uma possível relação entre a incidência média mensal de meningite e as variáveis climáticas precipitação pluviométrica, umidade relativa do ar e temperatura média do ar em alguns meses.

- Os melhores modelos de ajuste mensal foram obtidos para os meses de agosto, junho, maio e janeiro.

- De maneira preliminar, com a geração dos cenários climáticos futuros, pôde-se prever uma tendência para o comportamento da doença nos anos que se seguem conforme cenário normal e cenários influenciados pelas mudanças climáticas propostas pelo 40 relatório do IPCC, e considerar assim, que os casos da doença, como de maneira esperada, podem vir a aumentar de maneira gradativa.

- No outono (mar/abr/mai), no inverno (jun/jul/ago) e no verão (dez/jan/fev) o maior número de casos da doença, com o passar do tempo, encontra-se expresso no pior cenário predito pelo IPCC, seguido pelo melhor cenário, e por fim, no cenário normal, respectivamente.

- Durante a primavera (set/out/nov), observa-se um comportamento diferenciado, quando compara-se a evolução do número de casos nos três cenários, constatando-se nesta estação o menor nível de alterações entre estes, ou seja, os três revelaram totais muito 
próximos. Tal fato, possivelmente, ocorreu como consequência dos menores ajustes obtidos para os modelos matemáticos referentes aos meses da primavera.

- Todavia ,para traçar o comportamento de uma doença, é necessário considerar que inúmeras variáveis aleatórias como por exemplo fatores sócio-demográficos e outras influências ambientaissão responsáveis pela incidência dessa doença, sendo as mudanças climáticas apenas um dos muitos fatores importantes para a incidência de doenças infecciosas.

\section{REFERÊNCIAS}

BAENA, L. G. N. et al.Programa computacional para geração de séries sintéticas de dados climáticos. Engenharia na Agricultura, Viçosa, v.13, n.3, p210-202, 2005.

BRASIL. Ministério da Saúde. Secretaria de Vigilância em Saúde. In: Guia de

Vigilância Epidemiológica. 5. ed. Brasília, DF:FUNASA, 2002b. v.2, 902p. p.579-632.

BRASIL. Ministério da Saúde. Secretaria de Vigilância em Saúde. In: Guia de Vigilância Epidemiológica. 6. ed., Brasília, DF: MS, 2005a,. v.1, 816p. p.541-569.

CRUZ. G. C. F. Alguns aspectos do clima dos Campos Gerais. In: MELO, M. S.; MORO, R. S.; GUIMARÃ̃ES, G. B. Patrimônio Natural dos Campos Gerais do Paraná. 1. ed. Ponta Grossa: UEPG, 2007. Cap.5. p.59-72.

DALZOCHIO, T. Efeitos bioquímicos, imunológicos, moleculares e histológicos da exposição ao Enterovírus bovino em modelo animal. 2013, 50f. Tese (Mestrado em Qualidade Ambiental)- Universidade Feevale, Novo Hamburgo, 2013.

DANTAS, R. T. et al.Influência de variáveis meteorológicas sobre a incidência de meningite em Campina Grande - PB. Fafibe On Line, Bebedouro, v.3, n.3, p.1-6, 2007.

DOWNING, D.; CLARK,J. Regressão Linear Múltipla. In: Estatística Aplicada. 2. ed.

São Paulo: Saraiva, 2003. p.263-277.

EBI, K. L. et al.Adaptation to the infectious disease impacts of climate change. Climatic Chance, v.118, p.355-365, 2013.

GRASSO, M. et al.The Health effects of climate change: a survey of recent quantitative research. International Journal of Environmental Research and Public Health, Basel,v.9, n.5, p.1523-1547, 2012.

IPCC, 2007: Climate Change 2007: The Physical Science Basis. In: Contribution of working group I to the fourth assessment report of the Intergovernmental Panel on Climate Change [Solomon, S. et al. (eds.)]. Cambridge University Press, Cambridge, United Kingdom and New York, NY, USA, $996 \mathrm{p}$.

IRITANI, M.A. Modelação matemática tridimensional para a proteção das captações de água subterrânea. 1998, 200f. Tese (Doutorado em Recursos Minerais e Hidrogeologia)Universidade de São Pulo, São Paulo,1999.

KESSER, B. W. et al.Time course of hearing loss in an animal model of pneumococcal meningitis. J. Otolaryngol Head Neck Surg, v.120, n.5, p.628-637, 1999.

LABIAK, V. B. et al.Aspectos epidemiológicos dos casos de meningite notificados no município de Ponta Grossa - PR, 2001-2005. Cogitare Enfermagem, Curitiba, v.12, n. 3, p.306-312, 2007.

LUNA, E. J. A. A emergência das doenças emergentes e as doenças infecciosas emergentes e reemergentes no Brasil. Revista Brasileira de Epidemiologia, São Paulo, v.5, n.3, p.229$243,2002$. 
MENDONÇA, F. Aspectos da interação clima-ambiente-saúde humana: da relação sociedadenatureza e (in)sustentabilidade ambiental. Ra' e ga, Curitiba, v.11, n.4, p.85-99, 2000.

MENDONÇA, F. Clima, tropicalidade e saúde: uma perspectiva a partir da intensificação do aquecimento global. Revista Brasileira de Climatologia, v.1, n.1, p.100-112, 2005.

MENDONÇA, F.; PAULA, E. V. Meningites no estado do Paraná: uma leitura geográfica. Ra'ega, Curitiba, v.15, n.14, p.127-143, 2008.

MORAND, S. et al.Climate variability and outbreaks of infectious diseases in Europe. Scientific Reports, v.3, p.1-6, 2013.

OLIVEIRA, J. S. Variáveis meteorológicas e as ocorrências de doença meningocócica no município de Manaus de 2007 a 2009. 2011. 115 f. Tese (Mestrado em geografia na área de concentração: Geografia Física) - Faculdade de Filosofia, Letras e Ciências Humanas. Universidade de são Paulo, São Paulo, 2011.

PAULA, E. V. Evolução temporo-espacial das meningites no Estado do Paraná ao longo do século XX: abordagem climatológica. In: SIMPÓSIO BRASILEIRO DE SENSORIAMENTO REMOTO, 11., 2003, Belo Horizonte. Anais..., Belo Horizonte: INPE, 2003. p. 1415-1422.

PYKE, C.R. Interactions between habitat loss and climate change: implications for fairy shrimp in the central valley ecoregion of california, USA. Climatic Change, v.68, p.199-218, 2005.

RODÓ, X. et al.Climate change and infectious diseases: Can we meet the needs for better prediction? Climatic Change, v.118, n.3, p.625-640, 2013.

ROUQUAYROL, M. Z.; ALMEIDA FILHO, N. Epidemiologia e saúde. 6. ed. Rio de Janeiro: MEDSI: Guanabara Koogan, 2003. 708 p.

SANTOS, A.V. dos. Meningites. 2007. 72f. Trabalho de Conclusão de Curso (Graduação em Farmácia) - Centro Universitário das faculdades Metropolitanas Unidas, São Paulo, 2007.

SECRETARIA DE ESTADO DA SAÚDE DE SÃO PAULO. Divisão de Doenças de Transmissão Respiratória, do Centro de Vigilância Epidemiológica "Prof. Alexandre Vranjac", Coordenadoria de Controle de Doenças e INSTITUTO ADOLFO LUTZ. Meningites virais. Revista de Saúde Pública, São Paulo, v.40, n.4, p.748-750, 2006.

STOCCO, C. et al.Influência de variáveis climáticas sobre a incidência de meningite e sua distribuição espacial do município de Ponta Grossa- PR, 2001- 2005. Saúde e Sociedade, São Paulo, v.19, n.1, p.84-93, 2010.

VIEIRA, J. F. S. Incidência de meningite em pacientes de 0-12 anos no instituto de medicina tropical de Manaus. Arquivos de Neuro-Psiquiatria, São Paulo, v.59, n.2A, p.227-229, 2001.

VIRGENS FILHO, J. S. das. et al.Desempenho dos modelos Cligen, Lars-WG e PGECLIMA_R na simulação de séries diárias de temperatura máxima do ar para localidades do estado do Paraná. Engenharia Agrícola, Jaboticabal, v.33, n.3, p.538-547, 2013. 